\title{
Prediction of Eating Behaviors Among High-School Students Based on the Constructs of Theory of Planned Behavior
}

\author{
Ali Taghipour, ${ }^{1}$ Mohammad Reza Miri, ${ }^{2}$ Mahdieh Sepahibaghan,, ${ }^{3,}$ Mohammad Vahedian-Shahroodi, \\ Elahe Lael-Monfared, ${ }^{5}$ and Sakineh Gerayloo ${ }^{6}$ \\ ${ }^{1}$ Health Sciences Center, Department of Biostatistics and Epidemiology, Faculty of Health, Mashhad University of Medical Sciences, Mashhad, IR Iran \\ ${ }^{2}$ Department of Public Health, Faculty of Public Health, University of Birjand, Birjand, IR Iran \\ ${ }^{3}$ Student Research Committee, Faculty of Health, Mashhad University of Medical Sciences, Mashhad, IR Iran \\ ${ }^{4}$ Health Sciences Research Center, Department of Health and Management, Faculty of Health, Mashhad University of Medical Sciences, Mashhad, IR Iran \\ ${ }^{5}$ Department of Public Health, Torbat Heydariyeh University of Medical Sciences, Torbat Heydariyeh, IR Iran \\ ${ }^{6} \mathrm{PhD}$ Student of Health Education and Promotion, Faculty of Health, Shahid Sadoughi University of Medical Sciences, Yazd, IR Iran \\ "Corresponding author: Mahdieh Sepahibaghan, MSc in Health Education and Promotion, Student Research Committee, Faculty of Health, Mashhad University of Medical \\ Sciences, Mashhad, Iran. E-mail: baharsepahi96@gmail.com
}

Received 2016 April 09; Revised 2016 June 28; Accepted 2016 July 23.

\begin{abstract}
Background and Aim: Adolescence is among the most critical periods of growth and development. In this period, the quality of nutrition goes down with age. Thus, it is really important to pay special attention to adolescents' nutritional status. This study aimed at identifying the predictors of eating behaviors among high-school students based on the theory of planned behavior.

Methods: This descriptive-analytic study was conducted in 2013 - 2014 in Birjand, Iran, on 457 female students. Participants were selected through two-stage cluster random sampling. A three-part instrument was used for data collection. The instrument contained items on participants' demographic characteristics, TPB constructs (namely attitude, subjective norms, perceived behavioral control, and behavioral intention), and eating behaviors. The data were analyzed by employing SPSS software (v. 16) and through conducting Pearson correlation and multiple linear regression analyses at the significance level of less than 0.05.

Results: The constructs of the Theory of Planned Behavior predicted 53.8\% and 30\% of the variances of behavioral intention and eating behaviors, respectively. The strongest and the weakest predictors of behavioral intention were perceived behavioral control $(\mathrm{P}<0.001$ and $\beta=0.56)$ and subjective norms $(\mathrm{P}<0.005$ and $\beta=0.05)$, respectively. The construct of eating behaviors was significantly correlated with all constructs of the Theory of Planned Behavior. The strongest predictor of eating behaviors was behavioral intention.

Conclusions: The findings of the present study suggest that the Theory of Planned Behavior can successfully predict students' behavioral intention and eating behaviors. The power of the theory in predicting intention is greater than its power in predicting behavior. All constructs of the theory were significant predictors of behavioral intention and therefore, all these constructs need to be taken into account when developing interventions.
\end{abstract}

Keywords: Theory of Planned Behavior, Eating Behaviors, Students

\section{Background}

Adolescence is the period of rapid growth and puberty (1) and is associated with massive physical and mental changes and even crises (2). Such changes are among the factors behind adolescents' nutritional health. In this period, body mass index doubles and thus, adolescents' need for nutrients increases considerably (2). Thus, nutritional deficiencies can increase the likelihood of developing many illnesses, even cancers, among adolescents (1). These facts highlight the importance of paying special attention to the nutritional status of adolescents (2).
Unhealthy eating habits such as low fruit consumption, breakfast skipping, high intake of junk foods and innutritious snacks, and following strict weight-loss diets are very common among adolescents (3). Studies on Iranian adolescents have revealed their inferior nutritional status. For instance, a study in Isfahan showed that $90 \%$ of students had unhealthy eating behaviors (2). Another study on adolescents in Zanjan, Iran, also showed that adolescents in this province consumed inadequate amounts of different food groups (4).

An absolute prerequisite to healthy eating is the precise identification of influential factors on eating behav- 
iors (5). Given the complexity of healthy eating behaviors, appropriate models and theories are needed for shaping and reinforcing them (6). One of these theories is the theory of planned behavior (TPB). This theory was developed in 1980 by Ajzen and Fishbein (7). It is among the most important theories in the area of food choice, the predictive power of which has been assessed and confirmed in many sociological and behavioral studies (3). For instance, Mullan et al. (2013) found that the constructs of TPB predicted $42.2 \%$ and $57 \%$ of the variances of intention and behavior, respectively (8).

TPB holds that behavioral intention is the most important predictor of behavior (3). Three main predictors of behavioral intention in TPB are attitude (i.e. perceived desirable or undesirable outcomes of behavior), subjective norms (i.e. perceived social pressure for a behavior), and perceived behavioral control (i.e. perceived easiness or difficulty of showing desired behaviors) (8).

TBP has been used to identify factors contributing to some eating behaviors such as the consumption of snacks, sugar, chocolate, potato chips, and fruits (9). The theory has successfully predicted most eating behaviors. Although previous studies provided a detailed understanding about food choice behaviors among adolescents, little is known about their eating behaviors. Studies in Iran also mainly focused on certain types of eating behaviors such as fruit and vegetable consumption $(7,10)$. Moreover, although studies in other countries indicated the effectiveness of TPB in predicting students' eating behaviors (11), their findings may not be generalizable to Iranian adolescents. Thus, this study was designed and undertaken to identify the predictors of eating behaviors among highschool students based on TPB.

\section{Methods}

This descriptive-analytic study was conducted in 2013 - 2014 in Birjand, Iran, on seventh- and eighth-year highschool female students in order to predict their healthy eating behaviors based on TPB.

The Cochran's formula and the findings reported by Stead et al. (2005) (12) were used for sample size calculation. Stead et al. (2005) reported that TPB predicted $40 \%$ of the variance of behavior. Thus, with a p of 0.4 and a $\mathrm{d}$ of 0.05 , sample size was determined to be 368 persons. Nonetheless, we increased sample size to 457 students in order to compensate any probable attrition. Students were recruited through the two-stage cluster random sampling.

Initially, we obtained an introduction letter from Mashhad University of Medical Sciences, Mashhad, Iran, provided it to Birjand education office, Birjand, Iran, and subsequently secured the permission of the office for conducting the study. Then, a complete list was compiled of the names, addresses, and phone numbers of all high schools for girls in Birjand. After that, six schools were selected through simple random sampling. Finally, three classes (one seventh-year and two eighth-year classes) were randomly selected from each school.

A researcher-made three-part instrument was used for data collection. The instrument was developed through reviewing relevant textbooks, articles, and theses. The first part was a demographic questionnaire while the second contained items on different constructs of TPB, namely attitude (12 items), subjective norms (13 items), perceived behavioral control (7 items), and behavioral intention (6 items). The 13 items of the subjective norms were related to the effects of parents, siblings, school health instructors, peers, books and magazines, physicians, and nutrition specialists on students' eating behaviors. For attitude and subjective norms measurement, we used the questionnaires developed in 2011 by Hazavehei et al. (2). We added two questions to their subjective norms questionnaire and evaluated its validity and reliability. All items of the questionnaire were scored using a four-point Likert scale from 1 to 4 which respectively stood as 'Completely agree' or 'Very much' and 'Completely disagree' or 'Very low'.

The third part of the study instrument was related to eating behaviors. Given the wide variety of eating behaviors, we limited the items of this part to four main food groups i.e. fruits and vegetables, meat and cereals, milk and dairy products, and whole-grain bread. This part contained seven items on the frequency of using different foods. The possible answers to these items were 'Everyday', '3 - 4 times a week', '1 - 2 times a week', and 'Never', which were scored from 3 to 0 , respectively. The score of each construct was categorized as follows: 0 - 33.3: non-ideal; 33.4 66.6: relatively ideal; and 66.7-100: ideal (13).

The content validity of the study instrument was assessed via providing it together with the title and the aim of the study to a panel of fifteen nutrition and health education experts. Their comments were considered for revising the instrument. The reliability of the instrument was evaluated through internal consistency assessment, which showed that Cronbach's alpha values for the attitude, subjective norms, perceived behavioral control, intention, and behavior constructs were $0.72,0.82,0.74,0.75$, and 0.71 , respectively. Study data were analyzed by employing SPSS software (v. 16) and through conducting Pearson correlation and linear regression analyses at the significance level of less than 0.05 . 


\section{Results}

This study was done on 457 high-school female students, among whom 126 (27.6\%) were seventh-year and 331 (72.4\%) were eighth-year students. The father of the students had either university education (38\%), diploma (33.3\%), guidance-school (14.5\%), or primary educations (11.2\%) and only $2.9 \%$ were illiterate. These values among their mothers were $27.8 \%, 33.1 \%, 16.2 \%, 19.2 \%$, and $3.3 \%$, respectively. Most mothers were housewives (76.2\%) and $23.2 \%$ of them were employed. Moreover, most fathers were employees (50\%) and others were either selfemployed (34.3\%), laborer (7.7\%), or unemployed (2\%). Around $80.2 \%$ of the students had good eating attitudes. The highest attitude-related score was related to the role of milk and dairy products in bone strength so much so that more than half of the students (56\%) believed that consuming four glasses of milk and dairy products a day helps adolescents have strong bones.

Regarding subjective norms, the findings revealed that the most important significant others for the students were respectively their families, physicians, and nutrition specialists, while their peers' opinions were not as much important. Accordingly, most students answered a question relating to the importance of parents' and other family members' opinions about daily consumption of milk, meat, fruits and vegetables, bread, and cereals by selecting 'Extremely important' and 'Very important' options (43.7\% and 37.5\%, respectively). These values for physicians/specialists and peers were $78.8 \%$ and $21 \%$, respectively. Moreover, most students had great score on perceived behavioral control (74.8\%). The highest-and the lowest-scored items in the control dimension were related to the ability to use fruits and vegetables (with a mean score of 3.40 out of a possible total score of 4 ) and the ability to use foodstuffs that do not taste good (with a mean score of 2.66 out of a possible total score of 4 ).

The behavioral intention of most students was firm (82.1\%) and only $0.7 \%$ of them had a weak behavioral intention. Contrarily, a large portion of the students (24.2\%) had poor eating behaviors (Table 1). The findings revealed that eating behaviors and behavioral intention were positively correlated with all TPB constructs. Moreover, the strongest correlation of eating behaviors was with intention ( $r=0.49$; Table 2).

Multiple linear regression was used to predict behavioral intention using the attitude, subjective norms, and perceived behavioral control constructs. The findings revealed that all TPB constructs were significant predictors of behavioral intention with a total explained variance of $53.8 \%$. The strongest and the weakest predictors of behavioral intention were perceived behavioral control and sub- jective norms, respectively (Table 3 ).

On the other hand, the strongest predictors of eating behaviors were behavioral intention and attitude with the standardized beta values of 0.438 and 0.120 , respectively. However, the subjective norms and the perceived behavioral control constructs were not significant predictors of eating behaviors (Table 4).

\section{Discussion}

This study assessed the predictors of students' eating behaviors based on TPB. The findings revealed that most students had good eating attitudes and believed that milk and dairy product consumption significantly improves bone strength. In line with our findings, about $62 \%$ of the students in a study conducted by Hazavehei et al. (2011) also believed that daily consumption of four glasses of milk and dairy products helps adolescents have strong bones (14). Delvarianzadeh et al. (2011) also reported that $55.2 \%$ of their participating students had healthy eating attitudes (15).

Our findings also indicated that parents had the most significant role in shaping students' eating behaviors. Shahanjarini et al. (2009) also used an integrative approach to identify the determinants of junk food consumption among adolescents and found parents as the strongest predictor of subjective norms (3). Similarly, Berg et al. (2000) and Pawlak and Malinauskas (2008) suggested the significant role of parents in breakfast eating (16) and intention to eat vegetables (17). All these findings highlight the significant role of parents in shaping the eating behaviors of their children. Yet, Yarmohammadi et al. (2014) reported that among subjective norms, friends had the most significant effect on fast food consumption (18).

Most of our participants (74.8\%) had a good perceived behavioral control. Similarly, Yarmohammadi et al. (2014) showed that the mean score of perceived behavioral control was $80.5 \%$ (7). On the other hand, the lowest behavioral control mean score was related to the ability to use foodstuffs that do not taste good. Studies showed that taste is a significant factor behind adolescents' food choice (3). In agreement with our findings, Hosein-Nejad et al. (2008) reported that the lowest self-efficacy score was related to the use of the foods that do not taste good (19). Different studies supported that perceived behavioral control and selfefficacy may be similar constructs (20).

Study findings also evidenced students' firm behavioral intention. This finding can be attributed to the high scores of other TPB constructs (including attitude, subjective norms, and perceived behavioral control). TPB holds that these constructs can affect behavioral intention. Haz- 
Table 1. The Mean Scores of TPB Constructs

\begin{tabular}{|c|c|c|c|c|c|}
\hline TPB Constructs & Mean \pm SD & Possible Score & Ideal & Moderate & Poor \\
\hline Attitude & $35.14 \pm 5.14$ & $12-48$ & $321(80.2)$ & $79(19.8)$ & - \\
\hline Subjective norms & $31.12 \pm 6.48$ & $13-52$ & $121(30.4)$ & $274(68.4)$ & $5(1.2)$ \\
\hline Behavioral control & $21.32 \pm 4.93$ & $7-28$ & $299(74.8)$ & $98(24.5)$ & $3(0.7)$ \\
\hline Intention & $21.22 \pm 4.07$ & $6-24$ & $328(82.1)$ & $69(17.2)$ & $3(7 / 0)$ \\
\hline Behavior & $11.75 \pm 2.55$ & $0-21$ & $87(21.8)$ & $216(54)$ & $97(24.2)$ \\
\hline
\end{tabular}

Table 2. Correlations Among TPB Constructs

\begin{tabular}{lccc}
\hline Constructs & Attitude & Subjective Norms & Behavioral Control \\
\hline Subjective norms & $0.50^{\mathrm{a}}$ & 1 & \\
Behavioral control & $0.51^{\mathrm{a}}$ & $0.50^{\mathrm{a}}$ & 1 \\
Intention & $0.57^{\mathrm{a}}$ & $0.55^{\mathrm{a}}$ & $0.64^{\mathrm{a}}$ \\
Behavior & $0.42^{\mathrm{a}}$ & $0.32^{\mathrm{a}}$ & $0.38^{\mathrm{a}}$ \\
\hline
\end{tabular}

${ }^{\mathrm{a}} \mathrm{P}<0.001$

Table 3. Predicting Behavioral Intention Based on TPB Constructs

\begin{tabular}{l|c|c|c|c}
\hline TPB Constructs & T-Raito & Standardized Beta & P Value & $\mathbf{R}^{2}$ \\
\cline { 1 - 3 } Attitude & 5.952 & 0.260 & 0.000 & 0.538 \\
\cline { 1 - 3 } Subjective norms & 5.591 & 0.257 & 0.000 & 0.000 \\
\cline { 1 - 3 } Perceived behavioral control & 8.670 & 0.388 & 0
\end{tabular}

Table 4. Predicting Eating Behaviors Based on TPB Construct

\begin{tabular}{l|c|c|c|c}
\hline TPB Constructs & T-Raito & Standardized Beta & PValue & $\mathbf{R}^{2}$ \\
\cline { 1 - 4 } Attitude & 2.093 & 0.120 & 0.037 & 0.582 \\
\hline Subjective norms & 0.551 & 0.033 & 0.731 \\
\hline Perceived behavioral control & 0.344 & 0.021 & 0.30 \\
\cline { 1 - 3 } Intention & 6.451 & 0.438 & 0.000 & \\
\hline
\end{tabular}

avehei et al. (2011) also reported the relatively high score of behavioral intention among students (2).

Despite the high score of behavioral intention among study participants, only a small percentage of them had acceptable eating behaviors. Hazavehei et al. (2009) also found that $90 \%$ of their participating students had poor eating behaviors (14). An explanation for this finding is the fact that large increases in behavioral intention may be associated with moderate-level changes in behavior (8). In fact, the wide intention-behavior gap can be attributed to other internal and external factors contributing to the behavior as well as individuals' failure to act based on their intentions $(17,18)$.
Study findings revealed that the construct of eating behaviors was positively correlated with all other constructs of TPB. Mullan et al. (2013) and Sjoberg et al. (2004) also reported the same finding $(8,21)$. Our findings also showed that TPB constructs explained $53.8 \%$ of the total variance of behavioral intention and 30\% of the total variance of eating behaviors. Similarly, most studies on eating behaviors have reported that TPB successfully predicts behavioral intention and eating behaviors $(8,22)$.

Different factors have varying roles in predicting intention and behavior. It is supposed that the predictive power of the three constructs of TPB (i.e. attitude, subjective norms, and perceived behavioral control) depends 
on the type of behavior as well as on the immediate conditions (23). Our findings revealed that the strongest predictor of intention was perceived behavioral control while the predictive power of subjective norms was relatively low. These findings are in agreement with the findings reported by Bogers et al. (2004) (24). Mullan et al. (2013) also found perceived behavioral control as the strongest predictor of breakfast consumption intention among British adolescents (8). Contrarily, Huchting et al. (2008) reported that subjective norms construct was the strongest predictor of behavioral intention (25). Ayzenanf Fish (cited in Gerayllo, 2013) noted that the roles of subjective norms, attitude, and perceived behavioral control in predicting intention may vary according to the immediate context and the behavior (26).

Study findings also showed that the strongest predictor of eating behaviors was intention. This was an expected finding because TPB holds that the most significant predictor of behavior is intention to do the behavior (3). Mullan et al. (2013) also reported the same finding (8).

\subsection{Conclusions}

The findings of the present study suggest that TPB can successfully predict students' eating behaviors and thus, it can be used to develop interventions for promoting such behaviors. All TPB constructs were significant predictors of behavioral intention and therefore, all these constructs need to be taken into account when developing interventions. Moreover, as perceived behavioral control was the strongest predictor of behavioral intention, interventions for promoting students' behaviors need to be focused on promoting their sense of control. In addition, given the significant role of taste in predicting students' eating behaviors, adolescent health authorities in schools are recommended to develop strategies to manipulate this factor.

\section{Acknowledgments}

This article was extracted from a master's thesis approved by Mashhad University of Medical Sciences, Mashhad, Iran, with the ethical approval code of IR.MUMS.REC.1394.756. Hereby, we thank all people who helped us do this study, particularly the members of Mashhad school of health, as well as the administrators of Birjand education office.

\section{References}

1. Schmidt RL. Impact of nutrition education on dietary habits of female high school students. Masters Theses and Doctoral Dissertations. Ypsilanti, USA: Eastern Michigan University; 2010.
2. Hazavehei M, Pirzadeh A, Entezari MH, Hasanzadeh A. The effect of educational program based on BASNEF model on the nutritional behavior of students, (in Persian). J Zahedan Univ Med Sci. 2011;13(1):23-9.

3. Karimi Shahanjarini A, Shojaezadeh D, Majdzadeh R, Rashidian A, Omidvar N. Application of an integrative approach to identify determinants of junk food consumption among female adolescents, (in Persian). Iran J Nutr Sci Food Technol. 2009;4(2):61-70.

4. Amini K, Mojtahedi S, Mousaiefard M. Consumption of fruits, vegetables, dairy products and meat among high school students in Zanjan province, Iran, (in Persian).J Sch Public Health Inst Public Health Res. 2009;7(2):25-39.

5. van der Horst K, Kremers S, Ferreira I, Singh A, Oenema A, Brug J. Perceived parenting style and practices and the consumption of sugarsweetened beverages by adolescents. Health Educ Res. 2007;22(2):295304. doi: 10.1093/her/cylo80. [PubMed: 16908496].

6. Matlabi M, Sharifirad G, Mostavafi F, Mohebi S, Azadbakht L. Factors affecting fish consumption based on structures of health education, (in Persian).J Health Sys Res. 2013(4).

7. Yarmohammadi P, Sharifirad G, Azadbakht L, Pirzadeh A, Yarmohammadi P. Survey of factors associated with fruit and vegetable consumption among high school students using the theory of planned behavior in Isfahan, 2011-2012, (in Persian). J Health Sys Res. 2014(13).

8. Mullan B, Wong C, Kothe E. Predicting adolescent breakfast consumption in the UK and Australia using an extended theory of planned behaviour. Appetite. 2013;62:127-32. doi: 10.1016/j.appet.2012.11.021. [PubMed: 23219456].

9. Backman DR, Haddad EH, Lee JW, Johnston PK, Hodgkin GE. Psychosocial predictors of healthful dietary behavior in adolescents. $J$ Nutr Educ Behav. 2002;34(4):184-92. [PubMed:12217261].

10. Dehdari T, Kharghani Moghadam M, Mansouri T, Saki A. Survey of daily fruit consumption status among girl students who are living in dormitories and its predictors based on the theory of planned behavior constructs, (in Persian). Razi J Med Sci. 2013;20(106):10-9.

11. Hewitt AM, Stephens C. Healthy eating among 10 - 13-year-old New Zealand children: understanding choice using the Theory of Planned Behaviour and the role of parental influence. Psychol Health Med. 2007;12(5):526-35. doi: 10.1080/13548500601164396. [PubMed: 17828673].

12. Stead M, Tagg S, MacKintosh AM, Eadie D. Development and evaluation of a mass media Theory of Planned Behaviour intervention to reduce speeding. Health Educ Res. 2005;20(1):36-50. doi: 10.1093/her/cyg093. [PubMed:15198999].

13. Matlabi M. Evaluation of the theory planned behavior to promote fish consumption in women with a child in Gonabad city, (in Persian). Dissertation for the Award of the Doctor of Philosopy (PhD). Isfahan: Isfahan University of Medical Sciences; 2012.

14. Hazavehe M, Pirzadeh A, Entezari M, Hasanzadeh A, Bahreynian N. Investigating the knowledge attitude and nutritional practice of female middle school second graders in Isfahan in 2008, (in Persian). Knowl Health. 2009;4(3):24-7.

15. Delvarianzadeh M, Khosravi A, Razavian Zadeh N, Bolbol Haghighi N, Abbasian M, Taghavi N. Nutritional knowledge, attitude and practice of guidance-school girls of two regions in Iran, (in Persian). Knowl Health J. 2011(1).

16. Berg C, Jonsson I, Conner M. Understanding choice of milk and bread for breakfast among Swedish children aged 11-15 years, an application of the theory of planned behaviour. Appetite. 2000;34(1):5-19. doi: 10.1006/appe.1999.0269. [PubMed: 10744887].

17. Pawlak R, Malinauskas B. J Nutr Educ Behav. Predictors of intention to eat 2.5 cups of vegetables among ninth-grade students attending public high schools in eastern North Carolina. 2008;40(6):392-8. doi: 10.1016/j.jneb.2007.11.002. [PubMed:18984497].

18. Yarmohammadi P, Sharifirad GH, Azadbakht L, Morovati Sharifabad MA, Hassanzadeh A. Predictors of fast food consumption among high school students based on the theory of planned behavior, (in Persian). J Health Sys Res. 2012(4). 
19. Hosein Nejad M, Aziz zadeh Forozi M, Mohammad Alizadhe S, Haghdoost A. Role of self efficacy predictors in nutritional behaviors of kerman high school female students in 2006-2007 academic year, (in persian).J Shahid Sadoughi Univ Med Sci. 2008;16(3):320.

20. yekaninejad MS, Akaberi A, Pakpour A. Factors associated with physical activity in adolescents in Qazvin, an application of the theory of planned behavior, (in Persian). J North Khorasan Univ Med Sci. 2012;4(3):449-56.

21. Sjoberg S, Kim K, Reicks M. Applying the theory of planned behavior to fruit and vegetable consumption by older adults. J Nutr Elder 2004;23(4):35-46. doi:10.1300/J052v23n04_03. [PubMed: 15149939].

22. Kothe EJ, Mullan BA, Butow P. Promoting fruit and vegetable consumption. Testing an intervention based on the theory of planned behaviour. Appetite. 2012;58(3):997-1004. doi: 10.1016/j.appet.2012.02.012. [PubMed: 22349778]
23. Kim K, Reicks M, Sjoberg S. Applying the theory of planned behavior to predict dairy product consumption by older adults. J Nutr Educ Behav. 2003;35(6):294-301. [PubMed: 14642214].

24. Bogers RP, Brug J, van Assema P, Dagnelie PC. Explaining fruit and vegetable consumption: the theory of planned behaviour and mis conception of personal intake levels. Appetite. 2004;42(2):157-66. doi: 10.1016/j.appet.2003.08.015. [PubMed: 15010180].

25. Huchting K, Lac A, LaBrie JW. An application of the Theory of Planned Behavior to sorority alcohol consumption. Addict Behav. 2008;33(4):538-51. doi: 10.1016/j.addbeh.2007.11.002. [PubMed 18055130].

26. Gerayllo S. A study on determinants of self-care behaviors in patientswith knee osteoarthritis based on theory of planned behavior, (in Persian). Masters Thesis. Yazd University of Medical Sciences: Yazd University of Medical Sciences; 2013. 